\title{
An Exploration into Chinese EFL Students' Critical Thinking
}

\author{
Xu Suyun
}

\author{
Xi'an Jiaotong University City College
}

\begin{abstract}
Keywords: Critical Thinking in English classes; Critical Thinking Dispositions; Critical Thinking Skills; Measurement
\end{abstract}

\begin{abstract}
When English educators appeal for more efforts to develop college students' critical thinking in English classes, gaining a full understanding how much their critical thinking ability has achieved seems to be an indispensable task. This study applies Critical Thinking Disposition Survey (CTDS) and Critical Thinking Skills Tests (CTST) to measure Chinese EFL students' critical thinking abilities. The results show that those students have weak disposition to think criticallywith low passion to pursue truths and facts, little awareness to embrace innovative ideas, and scant confidence to frankly communicate, but show strong inspiration for new knowledge. Meanwhile, they are not proficient in fundamental and advanced levels of critical thinking skills - lack of judgment, application and analysis, but are surprisingly adept in some sub-skills. Probing into the status of their critical thinking in English is of great value for empirical researches into developing their critical thinking, and also for practices of nurturing innovation and entrepreneurship as well.
\end{abstract}

\section{Introduction}

Critical thinking has been regarded as one of the prerequisite of scientific researches and innovative development, and therefore has been set as a goal in Chinese higher education. Since Dewey initiated the concept of critical thinking in early $20^{\text {th }}$ Century, researchers have outlined its components, among which the most influential are Delphi's "Dual Structure" (Facione, 1990) and the "Three-Dimensional Model" by Elder \& Paul (2006). Wen (2009) even gears the model of "Meta-Critical Thinking + Critical Thinking" to Chinese students in their language learning.

Besides the fundamental researches into defining and measuring critical thinking, more and more studies have been diverted to the integration and cultivation of critical thinking in various courses. When integrated into English studies, critical thinking mainly functions as searching for English literature, gathering referential materials, reading and interpreting them, positioning and solving problems, and logically writing or reporting in English. It also prominently participates in identifying and evaluating information and ideas in both oral and written communication. In this sense, critical thinking is a comprehensive application of cross-cultural communication and logical thinking. Teachers should take critical thinking as one of their teaching objectives and cultivate students' disposition and develop their skills.

\section{Literature Review}

\section{Researches of CT in China}

English teachers in Chinese higher education have unanimously agreed that critical thinking is significant for college students and tried many efforts to enhance it in English study. Lin and He (2017) propose five language activities -comprehension, evaluation, extension, application and reflection -in college English teaching. They work out a framework to nurture college students' critical thinking in the general English courses, by training students to intellectually explore how to present their inner thoughts, which are usually complex and disordered, with clear and concise language. Some studies are focused on how to integrate critical thinking skills into various English courses, such as developing critical thinking in English writing (Mu, 2016), and promoting critical thinking in English Public Speaking and Debate (Tian \& Yang, 2015; Lin, 2012).

Most Chinese educators are pessimistic toward Chinese college students' critical thinking, claiming they are prevailingly of the "Syndrome of Critical Thinking Absence" (Huang, 2010). 
Such syndrome is attributed to the practice that teachers in English classrooms obviously despise thinking but overstate language flowing (Wen, 2015). It should be noted that there is still no effective model to nurture critical thinking in English classes (Gao \& Xu, 2015). However, Ren (2013) bravely challenges such viewpoints. She maintains the assertions that Chinese college students, especially English majors, perform poorly in exerting their critical thinking is not solidly supported by statistical evidences of reliability and validity. Then, to what extend have Chinese college students achieved in their critical thinking in English? It is in need that their critical thinking should be exactly measured rather than just be judged empirically and subjectively.

Few related studies about measuring critical thinking can be retrieved over CNKI, an authoritative academic online platform in China. Wen et al. (2010) compare English majors and students of other liberal arts in their critical thinking performance by using their own-made instrument of critical thinking skills, and hold that English majors strikingly outperform the latter. Confined by language proficiency and cultural difference, the widely-acknowledged measuring instruments of critical thinking, (such as California Critical Thinking Disposition Inventory (CCTDI), California Critical Thinking Skills Test (CCTST), Cornell Critical Thinking Test, and Watson-Glaser Critical Thinking Appraisal) find great difficulties to be applied among Chinese students. Due to the lack of effective CT measuring instruments, Chinese students' CT level still remained unknown.

It is early and blundering to explore ways to enhance CT in college English classes or the courses for English majors before probing students' CT disposition and performance. The cultivation of CT should be solidly based on the measurement rather than groundless speculation. Therefore, teachers should recognize the components and current status of CT, then can they set a clear and definite goal to promote their students' CT. This study attempts to measure the development of CT upon Chinese college students with a set of CT measuring instruments which have been carefully developed. It tries to disclose the disposition and skills of CT of regional students, which is expected to generate more empirical researches in this field.

\section{Measuring Instruments of CT}

The measurement of CT is preceded by its measuring instruments. Facione, an American research team of psychology, in early 1990s developed California Critical Thinking Disposition Inventory (CCTDI) and California Critical Thinking Skills Test (CCTST) which are now gaining wide popularity in the English world. The team even shapes and commercializes CCTDI and CCTST to different professions. However, the instruments, fully directed at western testees, are not applicable for Chinese, as the Chinese versions are rather obscure due to cultural and language differences.

Enlightened by Delphi's Dual Model (Facione, 1990), this study defines CT in two dimensions CT disposition and CT skills (see Diagram $1 \& 2$ ), and accordingly develops Critical Thinking Disposition Survey (CTDS) and Critical Thinking Skills Tests (CTST). Theoretically, CT disposition is featured by six fields: seeking the truth, opening the mind, analyzing problems, synthesizing facts, showing confidence, and aspiring to knowledge, each of which is comprehensively measured by eight items in CTDS. Those items are all in one Chinese statement followed by choices at Likert scale as "Strongly disagree", "Disagree", "Neither agree nor disagree", "Agree" and "Strongly agree". CT skills are classified into four levels: comprehension, judgment, reasoning, and application. With comprehension at the fundamental level and application at the advanced, reasoning and application are the intermediate that are the most frequently witnessed in language learning activities. The four stages respectively consist of concrete sub-skills (totally 15 sub-skills), each of which is tested by two multiple-choice items in English. Each item is presented as a setting and a question, and followed by four choices. Both the initial CTDS and CTST are pretested in two pilot studies covering over 500 target students and then revised and refined accordingly. The last pilot positively affirms CTDS (Cronbach's Alpha=0.898) and CTST (Difficulty Coefficient $=0.534$ ), which ensures that the two instruments are of great reliability and discrimination for Chinese college students. 
Diagram 1: Frame of CT Dispositions

\begin{tabular}{c|l|l}
\hline \multirow{4}{*}{\begin{tabular}{c|c} 
Seeking the truth \\
\cline { 2 - 3 } $\begin{array}{c}\text { Dispositio } \\
\text { ns }\end{array}$
\end{tabular}} & \begin{tabular}{l} 
Fields \\
\cline { 2 - 3 }
\end{tabular} & $\begin{array}{l}\text { Being willing to go beyond the surface to } \\
\text { explore the underlying truth, relevance and } \\
\text { causes. }\end{array}$ \\
\cline { 2 - 3 } & Analyzing problems & $\begin{array}{l}\text { Being ready to welcome different opinions, } \\
\text { evaluate the dissent, and take the reasonable } \\
\text { part. }\end{array}$ \\
\cline { 2 - 3 } & $\begin{array}{l}\text { Tending to differentiate facts and opinions, } \\
\text { causes and effects, the surface and the root. }\end{array}$ \\
\cline { 2 - 3 } & Showing confidence & $\begin{array}{l}\text { Being able to collect various factual } \\
\text { evidences and then working out the } \\
\text { differences, similarities or rules. }\end{array}$ \\
\cline { 2 - 3 } & $\begin{array}{l}\text { Aspiring } \\
\text { knowledge }\end{array}$ & $\begin{array}{l}\text { active in commung actication. } \\
\text { friends, books, and on-line resources. }\end{array}$ \\
\hline
\end{tabular}

Diagram 2: Frame of CT Skills

\begin{tabular}{|c|c|c|}
\hline \multirow{5}{*}{ Skills } & Levels & Sub-skills \\
\hline & Application & $\begin{array}{l}\text {-Solving problems } \\
\text { - Distinguishing causes and effects }\end{array}$ \\
\hline & Reasoning & $\begin{array}{l}\cdot \text { Predicting } \\
\cdot \text { Applying principles } \\
\cdot \text {-Inferring } \\
\cdot \text {-Inducing } \\
\cdot \text { Deducing }\end{array}$ \\
\hline & Judgment & $\begin{array}{l}\cdot \text { Discerning fallacies } \\
\cdot \text { Clarifying premises } \\
\cdot \text { Evaluating values } \\
\cdot \text { - Identifying facts and opinions }\end{array}$ \\
\hline & Comprehension & $\begin{array}{l}\cdot \text { Parsing } \\
\cdot \text { Summarizing } \\
\cdot \text { Defining } \\
\cdot \text { Interpreting }\end{array}$ \\
\hline
\end{tabular}

\section{Research Methods}

Adopting CTDS and CTST to probe into the current situation of critical thinking in Chinese college students, this study delivered 240 sets of paper instruments (one CTDS and CTST make up one set) to students in six Chinese universities, two of which are nationally prestigious, two are ordinarily ranked, and another two are less known and lowly ranked. Such distribution ensured that the chosen subjects were typical and representative enough. Those subjects come from different areas of the country and have generally studied English for at least 9 years, and therefore have developed their habit of critical thinking in English and gained some English proficiency. They study varied majors ranging from computer, architecture, medicine, to law and literature. After the delivery, 194 sets were called back, and only 155 were valid after being checked and shifted.

Then the measuring response were transformed into data and computed to be analyzed with SPSS for descriptive and analytical results. 


\section{Results}

About CT, people tend to have a general impression that some is very active in thinking and shows clear thoughts while another is sluggish in thinking and presents confusing ideas. The distance among language learners can be easily felt, but is rarely measured. By using two specially designed instruments which are reliable and valid as approved, this study has gained some precise findings.

\section{Critical Thinking Dispositions}

The statistical results as shown in Table 1 indicate a rather weak willingness to think critically among college students. The average of "Seeking the truth", "Opening the mind", "Analyzing problems", "Synthesizing facts", and "Showing confidence" is lower than 20, the half of the total sum. What should be noted is the figure of "Showing confidence", sadly at 13.0258, lagging far behind the others. Those clearly show Chinese college students lack awareness to think critically and have weak willingness to find out the truth of superficial facts and troublesome problems. They are not proficient at analyzing, gathering, and generalizing messy facts, neither do they have confidence to take such actions. Mu (2016) gains similar findings in his survey of critical writing among English majors that the majority are prevailingly not ready to question others' opinions, not competent to analyze exactly, and not confident to solve problems. His findings mostly coincide with the findings of this research. Another notable figure in Table 2 is the mean of "Aspiring to knowledge", at 21.7806, rather higher than other five fields. And the narrower Std. D. $(=5.16516)$ claims that Chinese college students popularly have strong desire to learn new knowledge, no matter how they learn it.

It's generally known Chinese students are passive in learning. Teachers are usually engaged in imparting knowledge by lectures and PPTs, discouraging students from questioning and reflecting upon the printed words. Even in English classes, where the teacher-student relation is less rigid and communication is praised, such learning activities as class or group discussion, topic presentation and public speaking are conducted just to push students to practice to achieve language proficiency and exactness. However, thoughts and ideas, the core and actual content of language expression, are less emphasized and even overlooked. As long as a student speaks fluently, he would gain acclamation, no matter his speaking is creative and meaningful or not. Meanwhile, in and outside the class, both teachers and students have preconceived notions that the learning materials are true, and are impossibly wrong. They take the form and information of the materials as true and learn them accordingly. They dare not challenge them, analyze them, and evaluate them, on their different stances. Just as pointed by Wen (2015), there are some problems with English teaching in colleges when critical thinking is valued. As aforementioned, college students have strong desires to learn the new. Teachers should cater for their desires by updating teaching notions and reforming teaching methods to encourage students' learning. For instance, English teachers can instruct students to share their interpretation or evaluation of cited materials, discuss possible ways to solve problems, and compare benefits and harms of the same topic from different perspectives.

Table 1: CT Dispositions

\begin{tabular}{l|c|c|c|c|c}
\hline \multicolumn{1}{c|}{ Dispositions } & Min. & Max. & S. Ttl. & Mean & Std. D. \\
\hline Seeking the truth & 2.00 & 30.00 & 40 & 15.0452 & 8.81066 \\
Opening the mind & 2.00 & 35.00 & 40 & 16.6774 & 9.43807 \\
Analyzing problems & 0.00 & 30.00 & 40 & 15.0645 & 8.75250 \\
Synthesizing facts & 2.00 & 32.00 & 40 & 15.1742 & 7.84687 \\
Showing confidence & 0.00 & 35.00 & 40 & $\mathbf{1 3 . 0 2 5 8}$ & 9.34195 \\
Aspiring to knowledge & 9.00 & 34.00 & 40 & 21.7806 & $\mathbf{5 . 1 6 5 1 6}$ \\
\hline
\end{tabular}

\section{Critical Thinking skills}

Some scholars (Huang, 2010) diagnose "Syndrome of CT Absence" among Chinese college students. Do Chinese students really perform so poorly in exerting CT in language learning? And if so, are they poor at all CT skills or just at any skills?

The results gained by this survey (see Table 2) show the subjects do perform disappointingly in the four levels of CT skills, with inadequate scores less than $60 \%$. They are especially incapable in 
conducting "Judgment" and "Application". Those results, to some extent, affirm the presence of "Syndrome of CT Absence" in Chinese students' language learning. They are less-skilled in thinking critically, in that they can't fully understand words in contexts and settings, but just interpret literally. They can't intensively analyze and judge the learning materials, and credulously take in others' viewpoints. They just focus on formally working out the cause-effect, but seldom compare and infer to figure out the major and minor causes.

Table 2: CT Skills

\begin{tabular}{l|c|c|c|c|c|c}
\hline \multicolumn{1}{c|}{ Skills } & Min & Max & Range & Mean & $\begin{array}{c}\text { Scoring } \\
\text { ratio }\end{array}$ & Std. D \\
\hline Comprehensio & 1.00 & 8.00 & $0.00-8.00$ & 4.3161 & $53.96 \%$ & 1.56982 \\
n & 0.00 & 7.00 & $0.00-8.00$ & 3.9935 & $49.92 \%$ & 1.33629 \\
Judgment & 1.00 & 9.00 & $0.00-10.00$ & 5.4452 & $54.45 \%$ & 1.94115 \\
Reasoning & 0.00 & 4.00 & $0.00-4.00$ & 1.8903 & $\mathbf{4 7 . 2 6 \%}$ & $\mathbf{1 . 0 2 2 9 0}$ \\
Application & 7.00 & 25.00 & $0.00-30.00$ & 15.6452 & $52.15 \%$ & 3.82022 \\
\hline Skill Total
\end{tabular}

The subjects show a bigger difference in "Reasoning" than other three skills, with Std. D at 1.94115, which can be attributed to their different discipline experience. It is commonly believed that students of science and technology are more capable in making formula inference and logical argument than their counterparts of liberal arts. The lowest Std. D (1.02290) and Scoring ratio $(47.26 \%)$ with "Application" prove the similar tendency of college students that they are not adept at analyzing causal relations and solving problems by thinking critically. The results wake us to the practice that teachers must strive to nurture and develop critical thinking among college students as they really lack such spirits and skills, and should encourage students to apply classroom theories to practical work.

\section{Critical Thinking Sub-skills}

The subjects are remarkably differentiated in the sub-skills (as shown in Table 3). The average scores of "Evaluating values" (0.7484), "Applying principles" (0.7484) and "Predicting" (0.7419) are far lagging behind of other sub-skills. They indicate that Chinese students are rather at a loss in citing popular values and abstract principles to support arguments (which are more common in American students), and unable to make reasonable speculations based on gained knowledge and experience. What's more, the difference of "Evaluating values" is not so big as claimed (Std. $\mathrm{D}=$ 0.59863), which claims such a defect is prevalent among Chinese students. That can be attributed to cultural difference between the western and the east. Brought up in their native culture, Chinese students do not agree on and take in the leading social values and principles upheld by American and English culture, or rather, they have antipathy against them as there are so many differences between them. So, when coming across references and evidences in English, they find it hard to accept and adopt western values and moralities. English teachers should be more tolerant toward their inadaptability, instead of abruptly and indiscriminately injecting western culture into the young students, though western culture is indispensable for English learning. Those students should be praised for their confidence in their native culture, but also be instructed as how to assimilate the essence and reject the dross of western values and principles. 
Table 3: CT Sub-skills

\begin{tabular}{l|c|c|c}
\hline \multicolumn{1}{c|}{ Sub-skills } & Range & Mean & Std. D \\
\hline Interpreting & $0.00-2.00$ & 1.0581 & 0.73182 \\
Defining & $0.00-2.00$ & 1.2710 & 0.57332 \\
Summarizing & $0.00-2.00$ & 1.4387 & 0.66532 \\
Parsing & $0.00-2.00$ & 1.0968 & 0.75399 \\
Identifying facts and opinions & $0.00-2.00$ & 1.0581 & 0.79966 \\
Evaluating values & $0.00-2.00$ & $\mathbf{0 . 7 4 8 4}$ & $\mathbf{0 . 5 9 8 6 3}$ \\
Clarifying premises & $0.00-2.00$ & 1.2129 & 0.72959 \\
Discerning fallacies & $0.00-2.00$ & 0.9742 & 0.60247 \\
Deducing & $0.00-2.00$ & 1.4645 & 0.67687 \\
Inducing & $0.00-2.00$ & 1.0774 & 0.71655 \\
Inferring & $0.00-2.00$ & 1.4129 & 0.68174 \\
Applying principles & $0.00-2.00$ & $\mathbf{0 . 7 4 8 4}$ & 0.67989 \\
Predicting & $0.00-2.00$ & $\mathbf{0 . 7 4 1 9}$ & 0.70101 \\
Distinguishing causes and & $0.00-2.00$ & $\mathbf{0 . 9 1 6 1}$ & 0.71127 \\
effects & $0.00-2.00$ & $\mathbf{0 . 9 7 4 2}$ & 0.70202 \\
Solving problems &
\end{tabular}

The two most advanced sub-skills "Distinguishing causes and effects" and "Solving problems" also lag behind other sub-skills (with means of 0.9161 and 0.9742), less than the middle in the range. It can be inferred that students are less experienced in positioning complex causal relations and solving troublesome problems which are mainly based on such fundamental skills as comprehension and judgment. That defect should be attributed to the teaching in English class. Generally, teachers are so obsessed in imparting established knowledge that they skip over some controversial issues worthy of further discussion, analysis and comparison. Students are used to learning English words and grammars without thinking and analyzing deeply. So teachers should be blamed for their narrow horizons and rigid teaching notions. It is teachers who should make the first change by constantly being exposed to new opinions and professionally being trained for new skills.

Surprisingly, the subjects are performing well in exerting other sub-skills such as "Summarizing", "Inferring" and "Deducing" (with means over 1.4). Deviating from the stereotype of rote learning without reason, Chinese college students are adept at extracting general information from random materials as they are often trained to find topic sentences, generalize main ideas, summarize key points when reading intensively.

\section{Relation Between CT Dispositions and CT Skills}

CT dispositions, gradually developed by one's way of upbringing and education and long-shaped by his mother culture and social settings, are rather intrinsic and definite. In contrast, CT skills are more concrete and changeable, and can be acquired by purposeful training and teaching. The correlation study of disposition and skills arrives at their Pearson of 0.161(*) and Sig. (2-tailed of 0.046), which clearly claim they are related significantly in that dispositions decide what skills to be employed. This also reminds teachers it will not be an easy job to develop and improve their students' thinking skills against their hardened tendency of passive learning, inert thinking and reluctant searching.

Table 4: Correlation Between CT Disposition and CT Skills

\begin{tabular}{ll|r}
\hline & & \multicolumn{2}{|c}{ CT Dispositions } \\
\hline CT Skills & Pearson & $.161\left(^{*}\right)$ \\
& Correlation & .046 \\
\hline
\end{tabular}




\section{Conclusion}

When educators have agreed on the necessity of developing critical thinking in college students' English learning, we should start with clarifying how much those students have achieved in their critical thinking, and this should be done before teaching plans are carried out. It is precisely what this study is focused on. English teachers in China will be faced with an arduous task to teach their students how to think critically and innovatively who are diagnosed with "Syndrome of CT Absence". In principle, they should do their best to encourage students to indefatigably seek the truth, to bravely pose challenges and questions, to rationally absorb or reject introduced culture, etc. In practice, they can give students more exercises to go beyond textual language, examine facts and opinions, check preconditions of any arguments, and make rationalized predictions, but especially apply fundamental theories into solving problems. Some researchers have explored how teachers can collaborate with administrators and learners in drafting teaching syllabus and reforming teaching methodology. It's expected that more and more will join in contributing to strong critical thinking among Chinese college students.

\section{Reference}

[1] Dam, G.; Volman, M. 2004. Critical thinking as a citizenship competence: teaching strategies [J]. Learning and Instruction, 14: 359-379.

[2] Facione, P. A. 1990. Critical Thinking: A Statement of Expert Consensus for Purpose of Educational Assessment and Instruction -Executive Summary / "The Delphi Report" [M]. Millbrae, CA: The California Academic Press.

[3] Paul R \& Elder L. Critical Thinking: Learn the Tools the Best Thinkers Use [M]. New Jersey: Pearson Prentice Hall, 2006.

[4] Fan Nengwei, Wang Aiqin. 2017. Integration of English major curriculum design and critical thinking skill cultivation under the guidance of the National Criteria [J]. Foreign Language World, 1: 7-14.

[5] Gao Ying, Xu Ying. 2015. Constructing a conceptual framework for the development of foreign language majors' critical thinking [J]. Foreign Language Research, 2: 127-132.

[6] Huang Yuanshen. 2010. Calling for reforming English major curriculum--Revisiting "Syndrome of Critical Thinking Absence" [J]. Foreign Language World, 1: 11-16.

[7] Lin Xiao, He Lianzhen. On developing critical thinking in college English classes [J]. Journal of Xi'an International Studies University, 1: 61-66.

[8] Lin Yan. 2012. Oral English teaching and critical thinking development [J]. Foreign Languages and Their Teaching, 5: 29-33.

[9] Mu Congjun. 2016. Investigating English major students' critical thinking ability in academic writing [J]. Modern Foreign Languages, 5: 693-707.

[10] Ren Wen. 2013. Revisiting foreign language majors' critical thinking skills - a case study of English Public Speaking course [J]. Foreign Languages in China, 1: 10-17.

[11] Tian Zhaoxia, Yang Ling. 2015. Localization of English Public Speaking (EPS) at universities in China revisited: discovering the pathway to clear thinking and effective communication [J]. Foreign Language Education In China, 1: 33-41.

[12] Wen Qiufang, Wang Jianqin, Zhao Cairan, Liu Yanping, Wang, Haimei. 2010. A comparative study of critical thinking skills between English and other liberal arts majors [J]. Foreign Language Teaching and Research, 5: 350-355.

[13] Wen Qiufang, Wang Jianqin, Zhao Cairan. 2009. Constructing a theoretical framework of critical thinking directed at Chinese EFL students [J]. Foreign Language World, 1: 37-41.

[14] Wen Qiufang. On key issues about critical thinking development in college EFL classroom [J]. Foreign Language Learning Theory and Practice, 3: 6-12. 